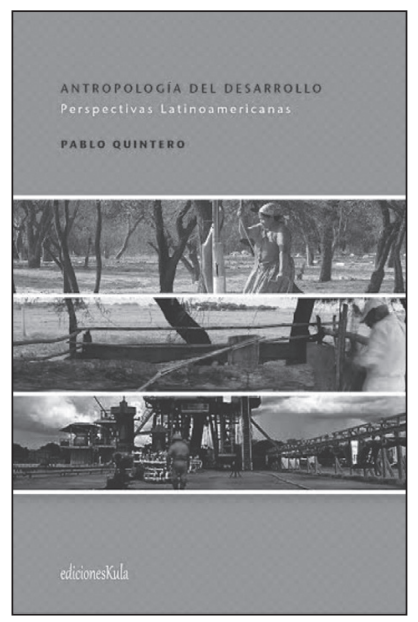

\title{
PABLO QUINTERO
}

Antropología del desarrollo: perspectivas

latinoamericanas

Buenos Aires: Kula Ediciones.

AÑO: 2015

ISBN: 978-987-27585-3-0

Páginas: 200

PAZ CONCHA ELIZALDE / INSTITUTO DE CIENCIAS ANTROPOLÓGICAS,

FACULTAD DE FILOSOFÍA Y LETRAS - UNIVERSIDAD DE BUENOS AIRES.

\section{Reseña}

En el actual contexto político latinoamericano, de «crisis de los progresismos», supuestos "fines de ciclo», o como quiera llamarse a la debacle institucional, económica y política que viven la mayoría de nuestros países y sus gentes - y sin que el nombre de tal proceso sea una cuestión menor-, las reflexiones sobre los errores cometidos o la falta de profundidad en los cambios que pretendían traer dichos gobiernos progresistas, son aristas de un debate que recién comienza. Sin embargo, desde una perspectiva decolonial, hay un factor común que hemos visto persistir y remecer en contradicciones a tales gobiernos y sus modelos de país. Lo cierto es que ni el socialismo bolivariano del siglo XXI, ni la fuerza intercultural que ha convertido en plurinacional al Estado de Bolivia, han logrado desembarazarse del «desarrollo» y sus inevitables consecuencias.

Entrampados durante lustros, parte de la intelectualidad latinoamericana se ha dedicado a intentar rescatar al desarrollo de sus nefastos y recurrentes resultados, apellidándolo con adjetivos salvíficos como «humano», «sustentable», «verde», «local», y una larga lista de calificativos que además de ser por sobre todo una expresión de deseo, han centrado la discusión entre un «buen y mal desarrollo», sin reparar en una nega- 
ción de lo que este realmente es, y cuán indisociable es su origen del capitalismo colonial/moderno.

Qué es y qué no es el desarrollo, cómo se anuda la urdimbre de su entramado de sentidos, cómo operan sus redes institucionales, cómo se hace carne, y cómo desmantelarlo para su análisis, son las preguntas que servirán de hilo conductor del último libro del antropólogo venezolano Pablo Quintero, puesto que este es el objeto de la Antropología del desarrollo. Ciertamente, la respuesta a estas preguntas es presentada con contundencia analítica, en una exposición teórica que refleja la madurez de un trabajo que ya cuenta con una década de profunda reflexión por parte del autor. El resultado que encontrará el lector es un libro modesto en su extensión y demoledor en sus argumentos, riguroso en su método. En este sentido, Antropología del desarrollo continúa el trabajo iniciado en La invención del Tercer Mundo de Arturo Escobar (1996), lectura obligada para introducirse a una crítica latinoamericana al desarrollo.

Aunque continuador del trabajo de Escobar, Quintero se ancla en el andamiaje conceptual del sociólogo peruano Aníbal Quijano. De allí toma el abordaje del análisis del desarrollo como una idea/fuerza producto de la colonialidad/modernidad, hijo predilecto de su meta-relato, pero no solo discurso. El desarrollo, como lo entiende Quintero, es una idea/ fuerza que, tanto ha moldeado nuestra subjetividad, como ha devenido en formas concretas y materiales de intervención; y ambas cuestiones son indisociables para el autor, incluso analíticamente.

El camino que nos presenta Quintero se divide en cuatro capítulos, comenzando por un recorrido a través de los debates en torno al desarrollo y su relación con la Antropología; tal revisión revelará el maridaje entre uno y otra, sucesión del origen colonial de nuestra disciplina, y nos pondrá al día con el estado del debate sobre estas cuestiones, clarificando posiciones. Del desarrollo de la antropología y la antropología del desarrollo culmina con una presentación de las líneas de investigación más recientes, emprendidas por intelectuales de todo el mundo, y que pueden enmarcarse en la Antropología del desarrollo, diferenciándose esta de la anterior Antropología para el desarrollo por una revisión crítica de su objeto de estudio.

Es preciso aclarar que la posición epistémico-política del autor se encuentra en el extremo de la crítica radical que, a nuestro criterio, precisan estos análisis y posiblemente desde allí provengan sus mejores aportes a estos debates. Sobre esta posición no quedarán dudas a partir del segundo capítulo, La teoría de la colonialidad del poder. Aquí, Quintero despliega su mapa conceptual y enmarca teóricamente su investigación dejando una suerte de plus: una acabada introducción a la colonialidad del poder. 
Aún si jamás se ha escuchado nombrar la categoría macro-histórica de colonialidad, se podrá seguir sin problema al autor en sus derroteros. Quintero, quien es sin lugar a dudas uno de los mejores exponentes de las ideas del sociólogo peruano, hace uso de la Teoría del poder de Quijano con maestría, articulando sus categorías en el análisis antropológico del desarrollo y ofreciéndonos una potente lectura social.

Los siguientes capítulos mostrarán la puesta en práctica de las ideas y críticas presentadas en los dos primeros. En El desarrollo y su linaje el autor va «destejiendo" la historia del desarrollo para urdir con la misma hebra su vinculación con el capitalismo y la colonialidad del poder, evidenciando su constitución como idea/fuerza, como un producto histórico y cultural. De igual forma, las principales teorías sobre el desarrollo de las disciplinas sociales encuentran aquí cita y revisión.

Para culminar, Quintero nos ofrece en Las estructuras elementales del desarrollo su propuesta teórico-metodológica. Alejándose de las estructuras elementales durkhemianas o lévi-straussianas para aproximarse a los grund, los fundamentos raigales marxianos, puesto que «[...] el desarrollo es en realidad una especifica configuración subjetiva que constituye uno de los fundamentos centrales de la cosmovisión colonial e imperial del sistema-mundo moderno» (p.157), y como tal, no puede abordarse como lo haríamos con la religión o el parentesco. Sin embargo, en tanto idea/fuerza, "se constituye en torno a un conjunto de estructuras elementales que a modo de principios constitutivos y organizacionales representan tanto el opus operatum como el modus operandi del desarrollo» (p. 157).

Las estructuras fundamentales del desarrollo serán entonces las lógicas epistémica y operacional que evidenciarán cómo el desarrollo y sus agentes piensan las sociedades y comunidades y cómo intervienen en ellas. En su propuesta, el autor nos presenta un conjunto de creencias rectoras y de acciones o prácticas en las que se materializan tales creencias, correspondientes a cada lógica. Sin embargo, estas lógicas y su articulación no deben entenderse como un mecanismo homogéneo o sistémico. Por el contrario, deben comprenderse a través de la heterogeneidad histórico-estructural de nuestro continente, presentándose de modo diverso, complejo, contradictorio e incluso discontinuo, pero siempre dentro de la totalidad histórico-estructural del patrón de poder de la colonialidad.

Dos cuestiones se pueden echar en falta en Antropología del desarrollo. Primero, la ausencia de casos en los que contrastar las propuestas del autor. Para ello, no hay más remedio que recurrir a sus trabajos anteriores, referenciados en el mismo libro. La segunda, es que pareciera enfocarse en intervenciones medianas y pequeñas del desarrollo y no en 
proyectos de gran envergadura. Consideramos que esto carece de importancia, precisamente, debido al abordaje desde las estructuras elementales del desarrollo.

Un punto interesante por revelarse en la propuesta teórico-metodológica de Quintero, es que su abordaje simultáneo desde las lógicas epistémicas y operacionales pudieran servir para otros objetos de estudio, a pesar de no cumplir exactamente con las mismas características del desarrollo. Es evidente que esto no es parte de los objetivos del autor: ofrecer un modelo analítico para las grandes instituciones de la Modernidad excede sus pretensiones. Sin embargo, es fácil pensar que su propuesta puede ser de gran utilidad para interpelar antropológicamente objetos como el derecho moderno o el sistema jurídico, por ejemplo, toda vez que estos comparten el mismo origen moderno/colonial de la colonialidad del poder. 